\title{
EDITORIAL: POR UM ESPAÇO PARA A PLURALIDADE DE PESQUISAS PÓS-GRADUANDAS EM CIÊNCIA POLÍTICA
}

Ao apresentar o volume duplo que marca o quarto ano de sua existencia, a Revista Eletrônica de Ciência Política também apresenta a mudança de seu corpo editorial. Neste momento em que uma nova equipe editorial assume os trabalhos, não o identificamos como uma ruptura, mas como uma natural renovação. A nova equipe, que se estabelece, tem como objetivo manter o esforço de divulgação da produção científica em Ciência Política, não apenas do Brasil, mas também latino-americana.

Contudo, não se pode esquecer a história que traça a Revista Eletrônica de Ciência Política. Afinal, não há renovação sem um passado, e um passado que não é findo, mas indica uma trajetória. Aqui, queremos deixar nossos agradecimentos ao primeiro corpo editorial, a Ícaro Engler e Giovanna Bonamim, criadores deste projeto, assim como a todos que com ele colaboraram no passado. Este agradecimento não visa apenas reconhecer o esforço fundante dedicado para empreender um periódico científico, considerando-se todas as suas dificuldades, mas também reconhecer a contribuição que deram para a divulgação científica de jovens pesquisadores, mestrandos, mestres e doutorandos da área.

Agradecemos também o apoio e colaboração que tiveremos na retomada deste projeto. O apoio institucional do Programa de Pós-Graduação em Ciência Política da Universidade Federal do Paraná, ao qual esta revista é vinculada, assim como sua contribuição consultiva. Ainda que inevitavelmente injustiçando outros, não mencionados, não podemos deixar de citar o apoio e os conselhos de Renato Monseff Perissinotto, vicepresidente da ABCP e entusiasta de primeira hora deste projeto, Michele Goulart Massuchin, atual editora da revista Agenda Política da UFSCar, e Gustavo Biscaia de Lacerda, ex-editor da Revista de Sociologia e Política.

Desde o princípio, a RECP espera constituir-se numa revista da comunidade científica e não apenas do Programa de Pós-Graduação ao qual se vincula. Tal política demandou um esforço de divulgação, chamando a comunidade a submeter novos trabalhos ao periódico. Quanto a esse esforço, nossa recompensa veio ao recebermos mais de 40 artigos, provenientes de 13 estados brasileiros e 23 diferentes instituições de ensino superior, além de três artigos provenientes do exterior. Isso não nos satisfaz apenas pelo reconhecimento da RECP como instrumento de divulgação científica, mas por demonstrar o crescimento e o fortalecimento da área de pesquisa em Ciência Política no Brasil. 
Nesta edição dupla, publicamos 13 artigos - sendo um deles internacional, em espanhol, proveniente do Equador. Sete deles compõem o dossiê que batiza este volume, “Estado e políticas públicas". Quatro deles se inserem na seção livre, enquanto dois estão na seção notas metodológicas. Destes números, um chama especial atenção. Nenhum destes artigos é de pesquisadores da própria instituição que edita esta revista. Mais do que ser um dos critérios de avaliação de periódicos da Capes, este número revela que esta revista efetivamente constitui-se como pertencente à comunidade científica da Ciência Política - e não veículo endógeno.

O dossiê Estado e Políticas Públicas contém sete artigos, de diferentes abordagens e temas. Uma característica nos salta aos olhos, em plena consonância com a perspectiva contemporânea da Ciência Política: todos os artigos presentes no referido dossiê são, em maior ou menor medida, empiricamente orientados.

$\mathrm{Na}$ apresentação do dossiê, Celina Souza, uma das mais importantes pesquisadoras do Brasil na área de Políticas Públicas, professora do IESP-UERJ, escreve texto que nos dá o ponto de partida deste debate, situando o leitor no campo.

No primeiro artigo do dossiê, Raphael Amorim Machado, doutorando da Unicamp, analisa, sob a perspectiva do presidencialismo de coalizão, os arranjos de coordenação das políticas de infraestrutura econômica logística no governo federal durante os dois mandatos de Lula. Os programas de investimento em infraestrutura tiveram, neste período, sua coordenação centralizada na Casa Civil e nos Ministérios do Planejamento e da Fazenda, deixando o Ministério dos Transportes em uma posição secundária.

Já Guilherme Quaresma Gonçalves, Samantha Haussmann Rodarte Faustino e Fábio César Araújo Costa, da UFMG, analisam a relação entre as políticas de tranferencia de renda e a taxa de defasagem idade-série, a partir do censo escolar. Com três modelos de regressão MQO, os autores captam que os valores mais significativos de redução da taxa de defasagem escolar, relacionados às transferências de renda, ocorrem quando considerados os estados do Nordeste.

No terceiro artigo do dossiê, Rafael Cardoso Sampaio, doutorando da UFBA, apresenta um levantamento todas as iniciativas relevantes em democracia digital no Brasil, dos poderes Executivo e Legislativo, nos três níveis federativos. Os resultados são classificados em seis categorias, que permitem a visualização de concentração ou ausência de iniciativas em certas áreas. Conclui que, embora seja possível verificar certo avanço nesta seara, os projetos são ainda pontuais. 
O perfil dos conselhos estaduais de políticas públicas no nordeste brasileiro é o tema de André Luis Nogueira da Silva e Damião Ernane de Souza. OS autores procedem com seu estudo com base na ESTADIC (Pesquisa de Informações Básicas Estaduais), base de dados recém-lançada pelo IBGE. O estudo comparativo analisa as características presentes ou ausentes nos conselhos em dezesseis áreas de políticas públicas, também cotejando o volume de transferências federais discricionárias.

Enquanto isso, Nayara Macedo e Noëlle Silva, mestrandas da UnB, produzem uma interpretação do Programa Minha Casa Minha Vida, à luz da perspectiva teórica das variedades de capitalismo. A resposta do Estado à desigualdade social, no contexto da crise econômica de 2008, aponta para a ação do Estado como propulsor da inclusão social, ao mesmo tempo em que mostra uma face hierárquica e centralizadora na tomada de decisões sobre o programa.

Já Taiana Ciscotto Lourenço, do CPDA-UFRRJ, sob uma perspctiva histórica, nos relata, a partir do caso do triângulo mineiro, as principais políticas estatais que tiveram influência na trajetória do setor canavieiro a partir da década de 1960 e seus desdobramentos. Seu objetivo é compreender a participação dessas políticas e do Estado na consolidação da modernização técnica e do agronegócio brasileiro.

E se até aqui cinco dos seis artigos se focaram em políticas públicas do (ou realizadas sob o) governo Lula, o artigo que encerra o dossiê analisa a agenda social nos governos Sarney e FHC. Oleg Abramov, da UFJF, procede com um relato contextual sobre a ascensão e a inflexão do regime de bem-estar social na primeira fase da República Nova, apontando estas diferenças e relacionando a ação dos atores aos ambientes institucionais em que estão inseridos.

$\mathrm{Na}$ seção livre, temos quatro artigos, tanto empíricos quanto, agora, teóricos. Eric Monné Fraga de Oliveira, do IESP-UERJ, propõe uma discussão teórica sobre a questão da racionalidade e o Estado moderno, a partir três autores fundamentais na teoria política: Hendrik Spruyt, Charles Tilly e Carles Boix. Já William Darío Chará Ordóñez, da Universidad del Cauca, na Colombia, e mestre pela Flacso do Equador, apresenta artigo internacional, em espanhol, sobre o poder político regional na provincia de Loja (Equador), entre 1984 e 2013, em que relaciona as mudanças na elite política com as reformas institucionais ocorridas no período. Enquanto isso, Alan Rangel apresenta uma discussão bibliográfica em que procura sintetizar os principais trabalhos sobre Estudos Legislativos no nível municipal, em especial no tocante ao comportamento dos legisladores. Por fim, Danielle Costa da Silva discute o papel dos direitos humanos no processo de 
desenvolvimento e sua relação com, na área das relações internacionais, a cooperação internacional para o desenvolvimento (CID).

Por último, temos a seção batizada Notas Metodológicas. Gostaríamos de chamar especial atenção para esta. $\mathrm{Na}$ Ciência Política, diferentemente de outras áreas em que esta discussão é por vezes quase secundária, o pensar sobre como fazer uma pesquisa, quais procedimentos adotar, ocupa lugar central. Acreditamos que dedicar uma seção inteiramente à discussão metodológica é fundamental em nosso campo e demonstra a importância que conferimos a este aspecto. Dois artigos estão presentes nesta seção.

Camila Massaro de Góes, doutoranda da USP, se pergunta: como compreender adequadamente o contexto e o significado das ideias do passado? A discussão teórica sobre o contextualismo linguístico da escola de Cambridge e crítica historicista - discussão esta inserida na disciplina da história das ideias - apresenta o diálogo crítico entre Quentin Skinner e o gramsciniano Joseph Femia.

Já Ranulfo Paranhos, Dalson Britto Figueiredo Filho, Enivaldo Carvalho da Rocha e José Alexandre da Silva Jr., da UFPE, em artigo que encerra com chave de ouro esta edição, de certa forma continuação ou decorrencia de outro excelente artigo publicado na edição 2012 desta RECP (“Levando Gary King a sério: desenhos de pesquisa em ciência política”), defendem que os desenhos de pesquisa em Ciência Política devem ser formados com o objetivo de produzir inferências causais falsificáveis - e explicam como fazê-lo.

Por fim, lembramos a missão desta revista, que é prover um espaço de publicação para pós-graduandos - pesquisas por vezes de alta qualidade que, por especificidades do campo, não consequem adentrar as revistas consideradas de ponta. Neste cenário, a RECP espera cumprir sua missão no cenário acadêmico nacional, propiciando a publicização de resultados de pesquisas em Ciência Política.

Antes de encerrar, contudo, não podemos deixar de ressaltar a impotância desta equipe, sem a qual esta edição não teria se viabilizado: Diego Silveira, Eric Gil Dantas, Flávia Bozza Martins, Jaqueline da Silva Borges, María Alejandra Nicolás e Paula Matoski Butture.

Ao leitor, desejamos uma boa leitura e boa pesquisa.

Márcio Cunha Carlomagno

José Augusto Hartmann

Editores-executivos 